\title{
Monte Carlo, Collapse Cone ve Pencil Beam Algoritmalarının Homojen ve İnhomojen Fantomda Açık Alan Ölçümleri
}

\author{
İsmail Faruk Durmuş ${ }^{1,2}$, Emine Dilara Atalay ${ }^{3}$ \\ ${ }^{1}$ Yeni Yüzyıl Üniversitesi Özel Gaziosmanpaşa Tıp Fakültesi Hastanesi, Radyasyon Onkolojisi \\ Bölümü, İstanbul \\ ${ }^{2}$ Nişantaşı Üniversitesi Meslek Yüksek Okulu, Radyoterapi Bölümü \\ ${ }^{3}$ Çanakkale Onsekiz Mart Üniversitesi, Fizik Bölümü
}

02.04.2019 Geliş/Received, 09.10.2019 Kabul/Accepted

\section{$\ddot{O} \mathbf{z}$}

Radyoterapide doz dağılımının doğru hesaplanması için küçük alan ölçümleri ve hesaplama algoritmalarının doğruluğu kritik öneme sahiptir. İnhomojen ortamlarda küçük alan dozimetrisindeki belirsizlikler ve zorluklar daha da artmaktadır. Bu çalışmada inhomojen ve homojen fantomlarda $6 \mathrm{MV}, 6 \mathrm{MV}-\mathrm{FFF}, 10 \mathrm{MV}$ ve $10 \mathrm{MV}-\mathrm{FFF}$ enerjileri ile $1 \times 1,2 \times 2,3 \times 3,4 \times 4$, $5 \times 5 \mathrm{~cm}^{2}$ alan boyutlarında CC04 ve CC01 Razor iyon odaları ile ölçümler alındı. Ölçümler ile Monaco tedavi planlama sisteminde Monte Carlo-Dose to Medium (MC-Dm), Monte CarloDose to Water (MC-Dw), Collapse Cone (CC) ve Pencil Beam (PB) algoritmaları ile yapılan hesaplamalar karşılaştırıldı. Homojen fantom su eşdeğeri RW3 katı fantomlardan, inhomojen fantom ise su eşdeğeri RW3 katı fantom ve akciğer eşdeğeri balsa fantom kullanılarak oluşturuldu. CC04 ve CC01 Razor iyon odaları ile hem homojen hem de inhomojen fantomda ölçümler değerlendirildiğinde, $\mathrm{MC}-\mathrm{Dm}, \mathrm{MC}-\mathrm{Dw}, \mathrm{CC}$ ve $\mathrm{PB}$ ile uyumlu sonuçlar elde edildi. Her iki fantomda da en büyük farklar $1 \times 1 \mathrm{~cm}^{2}$ alanlarda olduğu görüldü. İnhomojen fantomdaki sonuçlar homojen fantomdaki sonuçlarla karşılaştırıldığında uyum oranının homojen fantomda daha iyi olduğu görüldü. CC01 Razor iyon odas $10.01 \mathrm{~cm}^{3}$ hacme sahip ve merkezi elektrodu grafittir. Bu özellikleri ile CC01 Razor iyon odası ile yeterince güvenilir sonuçlar elde edilmiştir. Alan boyutu küçüldükçe ölçümler ve hesaplamalar arasındaki farklar artmaktadir.

Anahtar Kelimeler: İnhomojenite, Monte Carlo, CC01 Razor iyon odas1

\section{Output Measurements of Monte Carlo, Collapse Cone and Pencil Beam Algorithms in Homogeneous and Inhomogeneous Phantom}

\begin{abstract}
Accuracy of small field measurements and calculation algorithms is critical for accurate calculation of dose distribution in Radiotherapy. In inhomogeneous and homogeneous phantoms, measurements $\left(1 \times 1,2 \times 2,3 \times 3,4 \times 4,5 \times 5 \mathrm{~cm}^{2}\right.$ field sizes) were made with CC04 and CC01 Razor ion chambers using 6MV, 6MV-FFF, 10MV and 10MV-FFF energies. In the Monaco treatment planning system, dose distribution was calculated by Monte Carlo-Dose to


Medium (MC-Dm), Monte Carlo-Dose to Water (MC-Dw), Collapse Cone (CC) and Pencil Beam (PB) algorithms and compared with measurements. The homogeneous phantom water equivalent was generated from RW3 solid phantoms, and the inhomogeneous phantom was created using a water-equivalent RW3 solid phantom and a lung equivalent balsa phantom. When both the homogeneous and inhomogeneous phantom measurements were evaluated with $\mathrm{CC} 04$ and CC01Razor ion chambers, results consistent with MC-Dm, MC-Dw, CC and PB were obtained. The greatest differences in both phantoms were obtained in $1 \times 1 \mathrm{~cm}^{2}$ fields. When the results in the inhomogeneous phantom were compared with the results in the homogeneous phantom, the compliance ratio was observed to be better in the homogeneous phantom. The CC01 Razor ion chamber has a volume of $0.01 \mathrm{~cm}^{3}$ and its central electrode is graphite. With the CC01 Razor ion chamber, reliable results were obtained. As the field size becomes smaller, the differences between measurements and calculations increase.

Keywords: Inhomogeneity, Monte Carlo, CC01 Razor ion chamber.

\section{Giriş}

Radyoterapide (RT) kullanılan yüzde derin doz ve izodoz eğrileri su veya su eşdeğeri homojen ortamlarda elde edilmektedir. Fakat insan anatomisi farklı fiziksel ve radyolojik özelliklere sahip çeşitli doku ve organlardan oluşmaktadır. Bu doku ve organlar farklı elektron yoğunluğu, atom numarası ve kütle yoğunluğuna sahiptirler. Bu inhomojen yapılar foton ve elektronların transportunda ve soğurulmasında değişikliklere yol açmaktadırlar. Doz dağılımında olabilecek bu değişiklikler radyasyonun enerjisine, alan büyüklüğüne ve ortamın fiziksel özelliklerine bağlıdır (Frass, 1998) Doz dağılımındaki bu değişikleri hesaplamak ve düzeltmek için çeşitli yöntemler ve algoritmalar geliştirilerek tedavi planlama sistemlerinde (TPS) kullanılmaktadır. TPS ve hesaplama algoritmaları üç boyutlu konformal planlamalar için ilk kez 1990'lı yılların başlarında rutin olarak kullanılmaya başlanmıştır. Tedavide hastanın vücudunda soğurulan radyasyonun oluşturduğu doz dağglımı, TPS'nde hesaplama algoritmaları ile belirlenmektedir. Algoritmaların doğru doz hesaplaması RT'de başarı için çok önemli bir faktördür (Frass, 1998; IAEA, 2004; Bruinvis, 2005; Almond, 1999). TPS'de kullanılan algoritmalar üç ana başlıkta incelenebilir; düzeltme tabanlı, model tabanlı ve Monte Carlo (MC) doz hesaplama algoritmalarıdır. Düzeltme tabanlı algoritmalar, su fantomunda ölçülen derin doz eğrileri ve çeşitli derinliklerde alınan doz profillerinin interpolasyon ve ekstrapolasyon yapılarak doz hesabı yapmaktadırlar. Kısacası standart ölçümler ve düzeltme faktörleri ile doz dağılımı hesaplanmaktadır. Düzeltme tabanlı algoritmalar ICRU 91 de küçük alanların kullanıldığı stereotaktik tedaviler için kullanımının çok uygun olmadığı belirtilmiştir. Doku heterojenitesinin olduğu bölgelerde hedef hacim ve etrafında hatalı doz hesabına yol açabilmektedirler (ICRU, 2017; Lu, 2013). Model tabanlı algoritmaların fizik prensiplerine göre radyasyonla parçacık etkileşimini, enerji salınımını, ikincil elektronların dağılımını, saçılan ve aktarılan enerjiyi hesaba katmaktadırlar. Model tabanlı algoritmalarda iki tiptir. Birinci tip temel olarak heterojenite düzeltmeleri için Equvalent Path Lenght (EPL) ölçeklendirmesine dayanarak yapmaktadır. Genelde bu tip algoritmalarda elektronların yanal transportları modellenmemiştir. İkinci tip model tabanlı algoritmalarda yanal elektron transportları da dikkate alınarak daha doğru bir modelleme yapılmıştır. Son olarak MC doz hesaplama algoritması milyonlarca foton ve parçacı̆̆ın madde içerisinde iletiminin simülasyonunu hesaplayan programdır. Foton ve parçacıkların bireysel etkileşimlerinin olasılık dağılımını temel fizik kanunlarını kullanarak belirlemektedir. Simüle edilen parçacık sayısı ne kadar artarsa tahmin edilen doz dağılımın doğruluğu da o kadar artmaktadır. Ancak simüle edilen parçacık sayısı arttıkça, bilgisayarın hesaplama süresi de artmaktadır (Khan, 2010). MC algoritması lineer hızlandırıcı kafası ve hasta dahil olmak üzere tedavi 
geometrisinin tamamının modellenmesiyle kurulur. Genel olarak, konvansiyonel algoritmalara göre hesaplama zamanının çok fazla sürmesine rağmen, MC tekniği hasta içerisinde doz dağılımını hesaplamada en doğru altın standart algoritma olarak kabul edilmektedir. Özellikle akciğer içerisinde ve inhomojen dokuların yüzeylerinde belirli şartlarda parçacık dengesizliği meydana gelmektedir. MC algoritması hesaplama doğruluğunda önemli bir başarı sağlamaktadır (Khan, 2010; Ma, 2008).

RT'de genelde $4 \times 4 \mathrm{~cm}^{2}$ ile $40 \times 40 \mathrm{~cm}^{2}$ arasında alan boyutları kullanılmaktadır. Ancak RT'nin özel uygulamaları olan Yoğunluk Ayarlı Radyoterapi (YART) teknikleri ve Stereotaktik Radyoterapi (SRT) uygulamalarında $4 \times 4 \mathrm{~cm}^{2}$ den küçük alanlar kullanılmaktadır. Küçük alanlarda radyasyonun ölçülmesinde yüklü parçacık dengesizliği, ışın alanından bakıldığında kaynak alanının kısmi bloklanması, penumbranın artması ve detektör boyutunun alan boyutuna göre büyük olması, küçük alan dozimetrinin zorluklarıdır. Yüklü parçacık dengesi, madde içerisinde KERMA'nın absorbe doza dönüşmesindeki ilişkiyi göstermektedir. Maddede ortama serbest bırakılan kinetik enerjinin madde içerisinde soğurulması sonucu elektronik denge şartları oluşur. Başlangıçta KERMA maksimum, absorbe doz minimum seviyededir. Doz maksimum bölgesinde KERMA ile absorbe doz eşitlenir ve elektronik denge şartları sağlanır. Bu denge şartlarında belirli bir hacime giren parçacık sayısı ve parçacıkların enerjisi, o hacimden çıkan parçacık sayısı ve enerjisine eşit olur. Küçük alanlarda ikincil elektronların menzilleri, alan boyutundan daha büyük olduğundan yanal (ve longitudial) elektronik denge sağlanamaz (Ma, 2008; IAEA, 2017; Wilcox, 2008). Elektronik dengenin sağlandığı durumlarda doz profilinde plato bölgesi oluşur. Küçük alanların profilinde plato bölgesi oluşmaz. Küçük alanlarda kolime edilmiş bir kaynağın boyutunun belirli bir kısmı detektör görüş alanından görülemeyebilir. Eğer alan merkezinden kaynağın boyutunun tamamı görülemiyorsa, o zaman geometrik penumbra daha da artar. Kaynağın tamamının görülemediği durumlar, lineer hızlandırıcıda verim (output) ölçümlerinde farklı sonuçlara neden olmaktadır (Das, 2008a). Belirtilen nedenlerden dolayı küçük alanların dozimetrisinde kullanılan ölçüm sistemlerinin boyutları çok önemlidir. Alan boyutundan büyük ölçüm sistemleri ciddi belirsizliklere yol açabilmektedir. Akciğer gibi inhomojen ortamlarda küçük alanların dozimetrisi daha da zordur. Çünkü yanal saçılan elektronların menzilleri daha fazla olacağından sorunlar daha fazla olmaktadır. Küçük alan dozimetrisi için yüksek çözünürlükte, iyi ayırma gücü, doku eşdeğeri, lineer ve tekrarlanabilir cevabı olan sistemler tercih edilmelidir (Wilcox, 2008; Das, 2008a; Das, 2008b).

Çalışmamızda küçük alan dozimetrisinde kullanılan CC04 ve CC01 Razor iyon odalarının, homojen ve inhomojen fantomlarda küçük alan ölçümleri alındı. $6 \mathrm{MV}, 6 \mathrm{MV}-\mathrm{FFF}, 10 \mathrm{MV}$, 10MV-FFF enerjilerinin küçük alanlar ölçümlerinde homojen ve inhomojen ortamlarda MCDm, MC-Dw, Pencil Beam (PB), Collapse Cone (CC) algoritmalarının verifikasyonu sağlandı. İyon odaları ile alınan ölçümler ve algoritmalar arasındaki uyum araştırıldı.

\section{Materyal ve Yöntem}

TPS'lerinde kullanılan doz hesaplama algoritmalarının, doku içerisinde fotonun nasıl etkileştiğini incelemek için homojen ve inhomojen fantomlar oluşturuldu. Ayrıca radyasyonun belirlenen küçük alanlarda homojen ve inhomojen ortamlarda nasıl etkileştiği ve bu etkileşimleri hesaplayan algoritmaların doğruluğu araştırıldı.

Homojen fantom; 30x30 $\mathrm{cm}^{2}$ boyutlarında ve $1 \mathrm{~cm}$ kalınlığında su eşdeğeri RW3 fantomlardan 5 adet konuldu, üzerine iyon odası ile uyumlu fantom yerleştirildi ve son olarak üzerinde 4 adet $1 \mathrm{~cm}$ kalınlığında su eşdeğeri RW3 fantom konularak homojen fantom 
oluşturuldu (Şekil 2.1a). İnhomojen fantom; $30 \times 30 \mathrm{~cm}^{2}$ boyutlarında ve $1 \mathrm{~cm}$ kalınlığında su eşdeğeri RW3 fantomlardan 8 adet konuldu, üzerine akciğer eşdeğeri balsa fantomumdan 3 $\mathrm{cm}$ kalınlığında konuldu. Daha sonra iyon odası ile uyumlu fantom yerleştirildi. Son olarak üzerine de $3 \mathrm{~cm}$ kalınlığında akciğer eşdeğeri balsa ve onunda üzerine 5 adet $1 \mathrm{~cm}$ kalınlığında su eşdeğeri RW3 fantom konularak homojen fantom oluşturuldu (Şekil 2.1b). Homojen ve inhomojen fantomlar Siemens Biograph mCT (Knoxville, TN, USA) cihazında 1 mm kesit aralı̆̆ında tarandı.

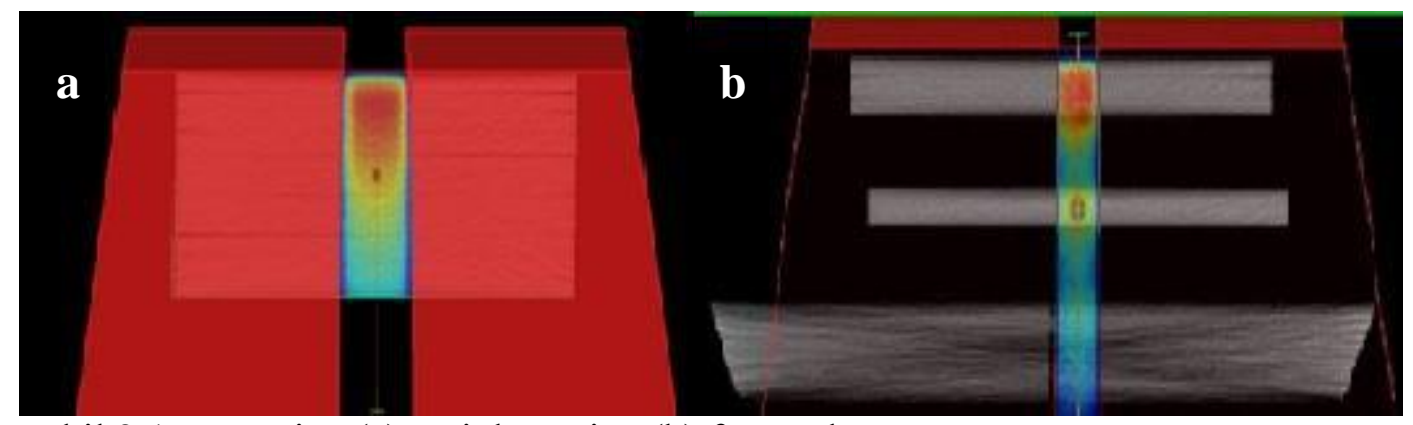

Şekil 2.1. Homojen (a) ve inhomojen (b) fantomlar

Çalışmamızda CC04 ve CC01 Razor iyon odaları ile homojen ve inhomojen fantomlarda Elekta Versa HD (Elekta, Crawley, England) lineer hızlandırıcısı kullanılarak ölçümler alındı. Versa HD cihazı farklı foton ve elektron enerjilerine sahip lineer hızlandırıcidır. $40 \times 40 \mathrm{~cm}^{2}$ alan boyutuna sahip 160 multi leaf kolimatöre (MLC) sahiptir. İyon odaları küçük hacimleri sayesinde küçük alan dozimetrisinde, doz gradientinin hızlı olduğu bölgelerde ve stereotaktik amaçlı ölçümler için kullanılan dozimetre sistemleridir. Genel olarak yüksek ayırma gücüne sahip ve su geçirmezdirler. Kullanılan iyon odalarının genel özellikleri Çizelge 2.1 de gösterilmiştir.

Çizelge 2.1. İyon odalarının özellikleri

\begin{tabular}{|c|c|c|c|c|c|c|}
\hline İyon Odaları & $\begin{array}{c}\text { Hacim } \\
\left(\mathrm{cm}^{3}\right)\end{array}$ & $\begin{array}{c}\text { Uzunluk } \\
(\mathrm{mm})\end{array}$ & $\begin{array}{c}\text { Çap } \\
(\mathrm{mm})\end{array}$ & $\begin{array}{c}\text { Duvar } \\
\text { Materyali }\end{array}$ & $\begin{array}{c}\text { Duvar } \\
\text { Kalınlığ } \\
1 \\
\left(\mathrm{gr} / \mathrm{cm}^{3}\right)\end{array}$ & $\begin{array}{c}\text { Merkezi } \\
\text { Elektrot } \\
\text { Materyal } \\
\mathrm{i}\end{array}$ \\
\hline CC04 & 0.04 & 3.6 & 2 & $\mathrm{C} 552$ & 0.070 & Grafit \\
\hline CC01 Razor & 0.01 & 3.6 & 1 & $\mathrm{C} 552$ & 0.088 & Grafit \\
\hline
\end{tabular}

İnhomojen ve homojen fantomlarda $6 \mathrm{MV}, 6 \mathrm{MV}-\mathrm{FFF}, 10 \mathrm{MV}$ ve $10 \mathrm{MV}$-FFF enerjileri ile $1 \mathrm{x} 1$, $2 \times 2,3 \times 3,4 \times 4,5 \times 5 \mathrm{~cm}^{2}$ alan boyutlarında $100 \mathrm{MU}$ ile CC04 ve CC01 Razor iyon odaları ile ölçümler alındı. Ölçümler ile aynı düzenekte Monaco 5.11 TPS'nde Monte Carlo-Dose to Medium (MC-Dm), Monte Carlo-Dose to Water (MC-Dw), CC ve PB algoritmaları ile hesaplatılarak karşılaştırıldı. Hesaplamalarda $0.2 \mathrm{~cm}$ grid boyutu kullanıldı.

\section{Bulgular ve Tartışma}

CC04 iyon odası ile homojen fantomda Şekil 3.1'de görülen sonuçlar değerlendirildiğinde, genel olarak MC-Dm, MC-Dw, CC ve PB ile uyumlu sonuçlar elde edildi. En büyük farklar $1 \times 1 \mathrm{~cm}^{2}$ alan boyutlarındaki ölçümlerde bulundu. 


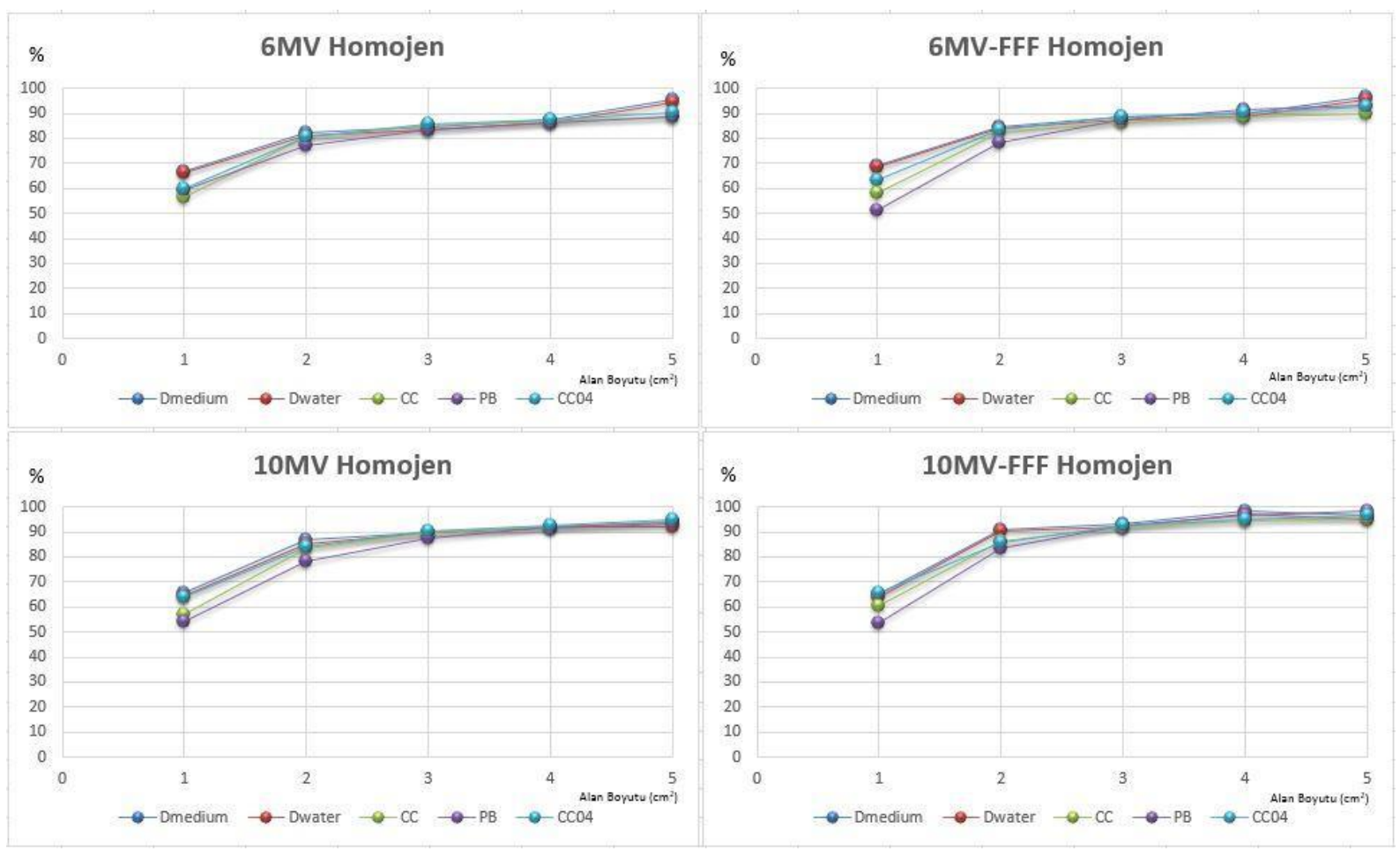

Şekil 3.1. Homojen fantomda CC04 iyon odası ile ölçümler

CC01 Razor iyon odası ile homojen fantomda ölçümler değerlendirildiğinde, genel olarak MC-Dm, MC-Dw, CC ve PB ile uyumlu sonuçlar elde edildi. En büyük uyumsuzluk $1 \times 1 \mathrm{~cm}^{2}$ alanlarda görüldü. $6 \mathrm{MV}$ ve $6 \mathrm{MV}$-FFF enerjilerinde $1 \times 1 \mathrm{~cm}^{2}$ alanlarda bu uyumsuzluğun arttığı gözlendi. Homojen fantomda CC04 iyon odalarına göre CC01 Razor iyon odası ile daha iyi sonuçlar elde edildi. 


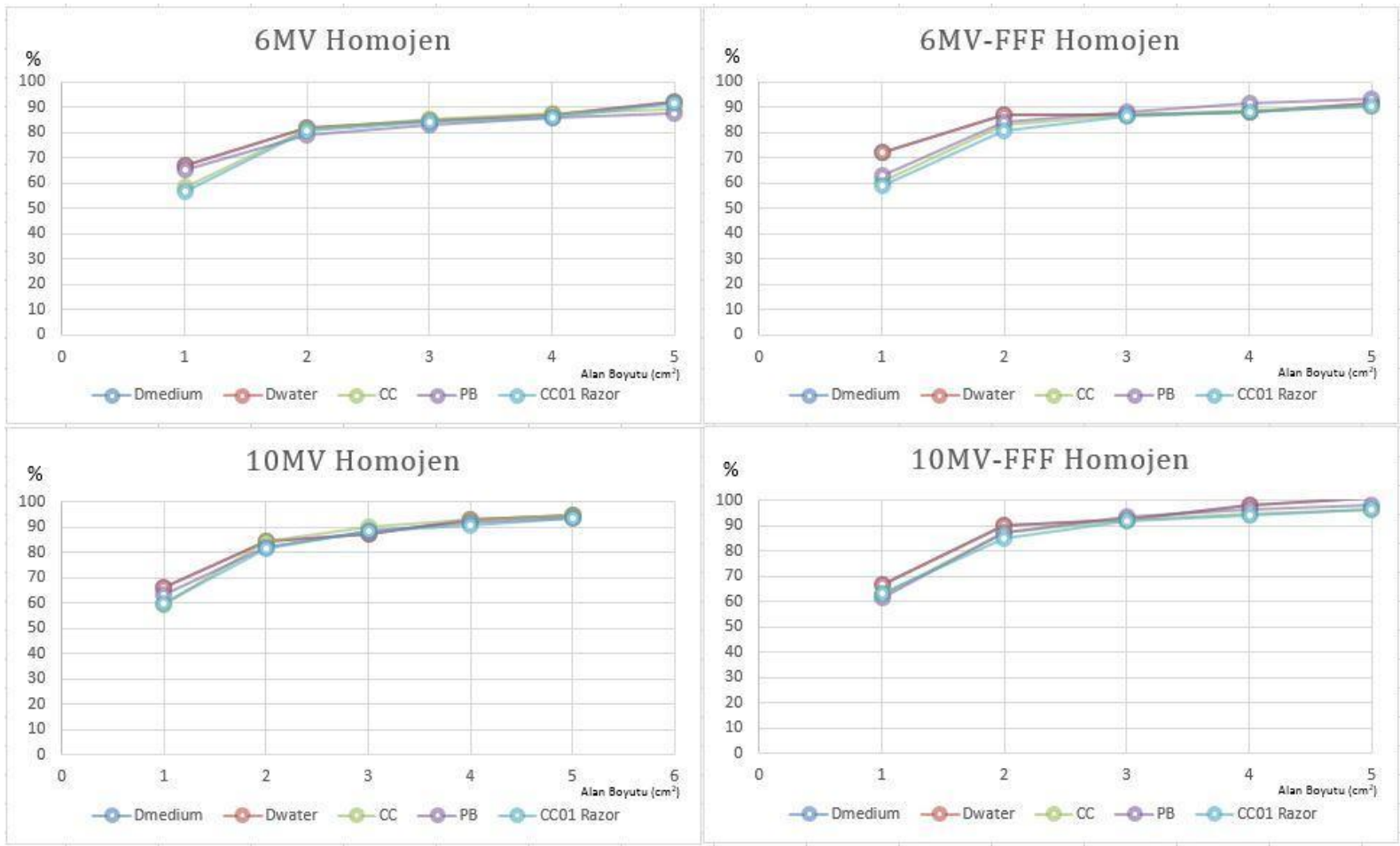

Şekil 3.2. Homojen fantomda CC01 Razor iyon odası ile ölçümler

CC01 Razor iyon odası ile inhomojen fantomda şekil 3.3'de görülen sonuçlar değerlendirildiğinde, genel olarak MC-Dm, MC-Dw, CC ve PB ile uyumlu sonuçlar elde edildi fakat homojen fantomdaki sonuçlarla karşılaştırıldığında uyum oranı daha azdır. En büyük uyumsuzluğun $1 \times 1 \mathrm{~cm}^{2}$ alanlarda olduğu görüldü.
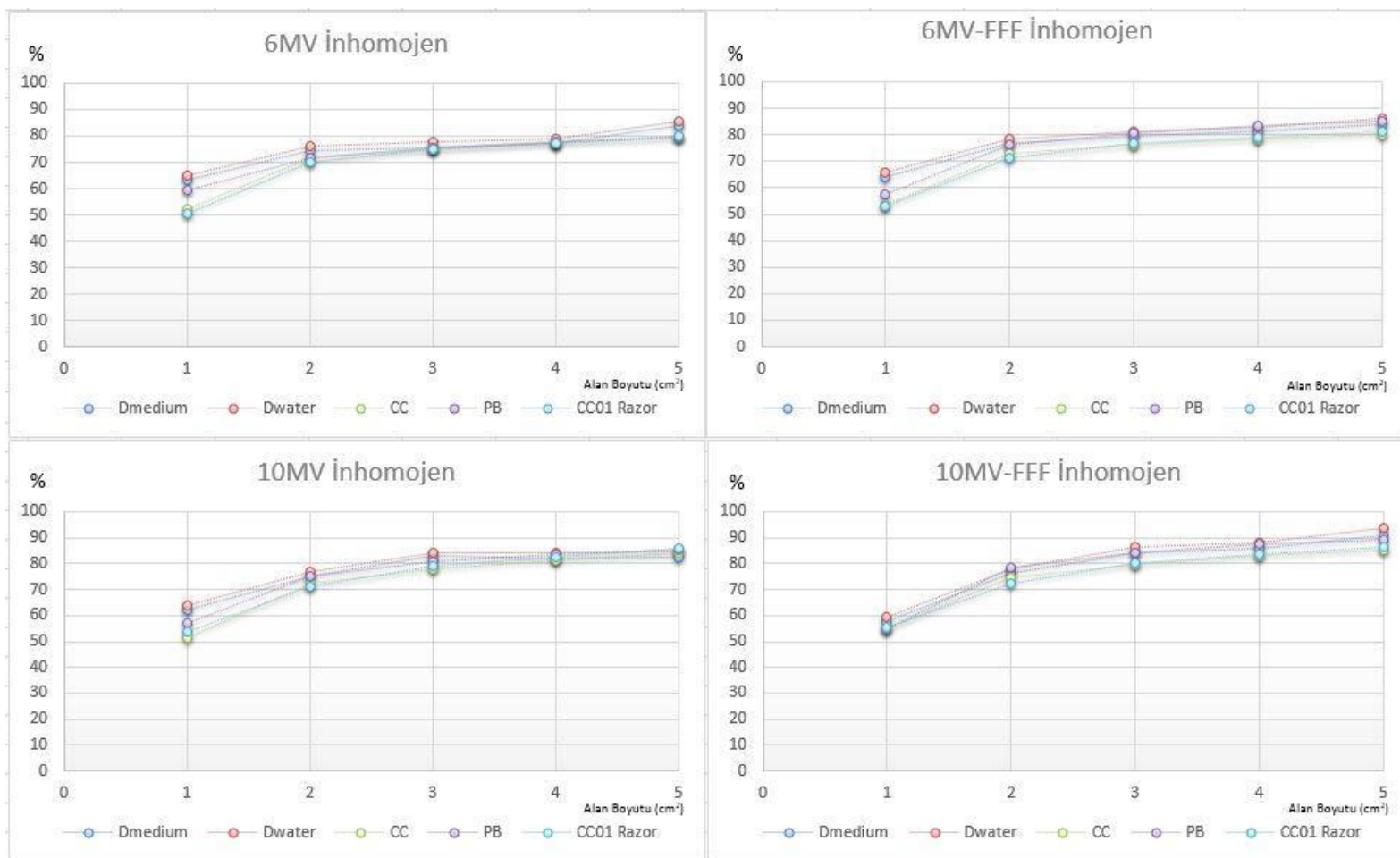

Şekil 3.3. İnhomojen fantomda CC01 Razor iyon odası ile ölçümler 
CC04 iyon odası ile inhomojen fantomda şekil 3.4'de görülen sonuçlar değerlendirildiğinde, genel olarak MC-Dm, MC-Dw, CC ve PB ile uyumlu sonuçlar elde edildi fakat homojen fantomdaki grafiklerle karşılaştırıldığında uyum oranı daha azdır. En büyük uyumsuzluk 1x1 $\mathrm{cm}^{2}$ alanlarda görüldü. CC01 Razor iyon odası ile $1 \mathrm{x} 1 \mathrm{~cm}^{2}$ alanlarda inhomojen ortamda daha iyi sonuçlar elde edildi.

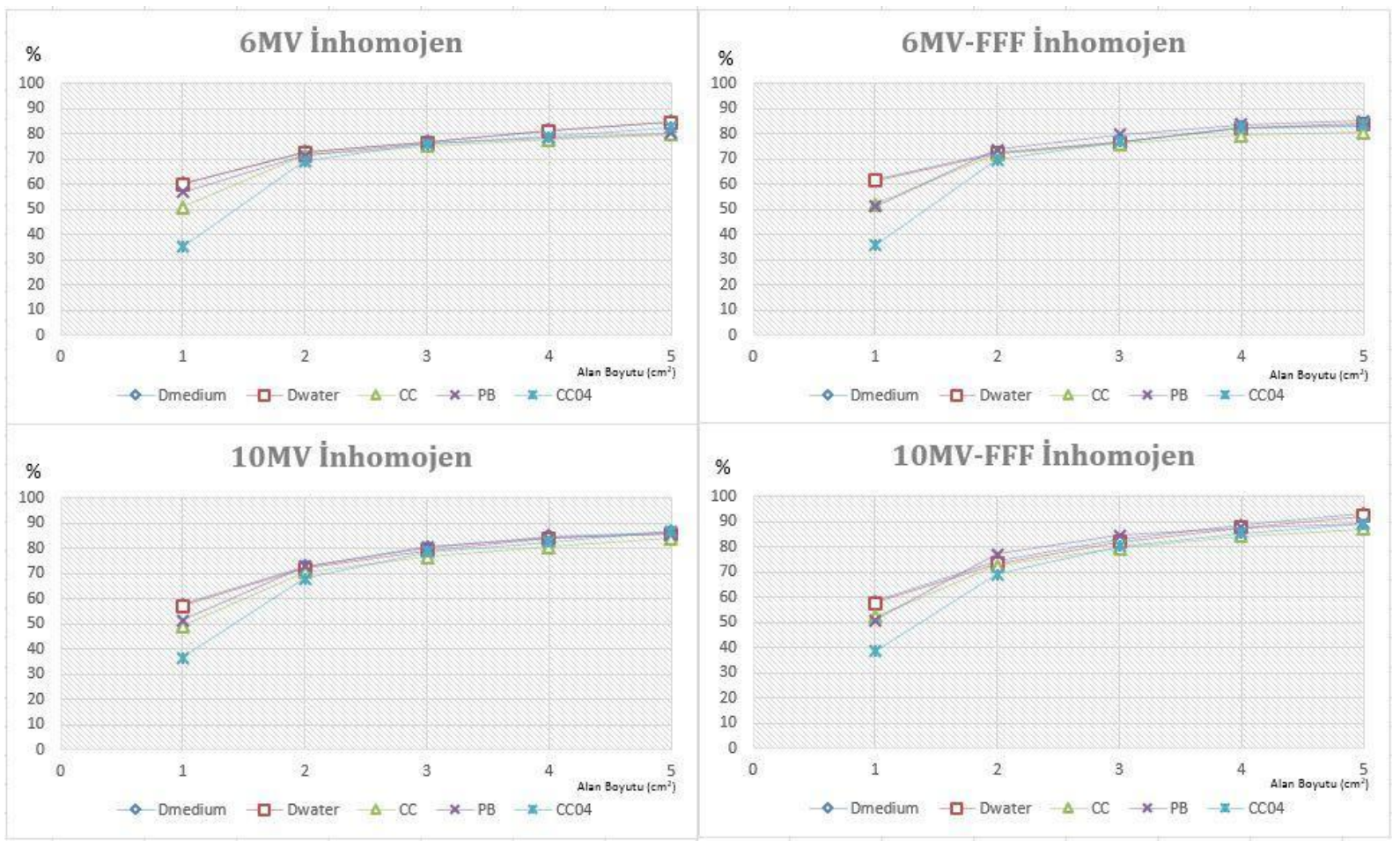

Şekil 3.4. İnhomojen fantomda CC04 Razor iyon odası ile ölçümler

\section{Sonuç}

Homojen fantomda yapılan ölçümlerde $1 \times 1 \mathrm{~cm}^{2}$ alan boyutlarındaki ölçümler hariç tüm alan boyutlarında algoritmalar ve ölçümler arasında uyum oranının yüksek olduğu gözlendi. 10MV ve $10 \mathrm{MV}$-FFF enerjilerde $6 \mathrm{MV}$ ve $6 \mathrm{MV}-\mathrm{FFF}$ enerjilerine göre $1 \times 1 \mathrm{~cm}^{2}$ alanda daha uyumlu sonuçlar elde edildi. Yeni geliştirilen CC01 Razor iyon odası için özellikle $1 \times 1 \mathrm{~cm}^{2}$ alan ölçümlerinde daha doğru sonuçlar elde edildi.

İnhomojen fantomda yapılan ölçümlerde algoritmalar ve ölçümler arasında uyumlu sonuçlar elde edildi. Fakat özellikle $1 \times 1 \mathrm{~cm}^{2}$ alan boyutlarında yapılan ölçümlerde PB ve CC algoritmalarının, MC algoritması ile aralarında farkların olduğu görüldü. CC04 iyon odası 1x1 $\mathrm{cm}^{2}$ ölçümlerinde \%20'lere yakın farklar bulundu. CC01 Razor iyon odası ile daha uyumlu sonuçlar elde edildi. Literatür taraması yapıldığında aşağıdaki belirtilen çalışmalarla sonuçlarımızın uyum içerisinde olduğu görüldü. Lax ve ark. akciğer SBRT uygulamalarında $\mathrm{CC}, \mathrm{PB}, \mathrm{MC}$ algoritmalarının doz dağılımlarındaki farklılıkları incelemişlerdir. PB algoritmasının dozu daima daha fazla hesapladığını bulmuşlardır. Fantom çalışmasında akciğer eşdeğeri inhomojen ortamlarda GTV de \%10, GTV dışında \%30'lara yakın fark bulmuşlardır (Lax, 2006). Kim ve ark. inhomojen ortamda TPS'de kullanılan PB, CC ve MC algoritmaların doz dağılımları üzerine etkilerini araştırmışlardır. 5 Akciğer ve 5 meme kanseri hastasına $6 \mathrm{MV}$ enerjide YART planlamışlardır. Genel olarak CC ve MC ile benzer MU değerleri bulunurken, PB ile daha düşük MU değerleri elde etmişlerdir. PB algoritması, MC algoritmasına göre \%12-20 arasında dozu fazla hesaplamıştır. En doğru hesaplamaların MC 
doz algoritması ile elde etmişlerdir (Kim, 2015). Chen ve ark. 15MV enerjide PB ve MC algoritmaları ile akciğer SBRT'de doz dağılımları karşılaştırmışlardır. Tedavi planının verifikasyonu için EDR2 film ve inhomojen fantom kullanmışlardır. Doz profillerini ve doz dağılımlarını karşılaştırmışlardır. 35 Akciğer SBRT hastası için Eclipse planlama sisteminde PB algoritması ile yapılan planları MC algoritması ile tekrar hesaplatmışlardır. PB ile film profil ölçümlerinde farklar $+\% 15$ 'lere kadar farklar olabilmektedir. $\mathrm{MC}$ ve film profil ölçümlerinde bu farklar <\%1'dir. 35 Akciğer SBRT planında PB algoritması dozu fazla hesaplamıştır. Özellikle küçük boyuttaki PTV'lerde bu farklar çok daha fazla olmaktadır [Chen 2010]. Dobler ve ark. küçük akciğer lezyonlarının tedavisinde farklı doz hesaplama algoritmalarını karşılaştırmak ve doğrulamak için akciğer fantomu üzerine 9 alanlı konformal plan hazırlamışlardır. Planların verifikasyonu için EBT film kullanmışlardır. PB algoritması $\% 15$ dozu fazla hesaplamıştır. CC algoritması EBT filme göre -\%8, MC algoritması ise -\%3 farkla dozu hesaplamışlardır (Dobler, 2006). Chetty ve ark. SBRT ile tedavi edilen 133 akciğer hastasında doz dağılımlarını retrospektif olarak tekrar hesaplamışlar ve tümör kontrol olasılığı modelini kullanarak doz ile tedavi sonuçları arasında bir ilişki kurmayı amaçlamışlardır. PB algoritmasıyla 4 fraksiyonda 48 Gy (BED:106 Gy) tedavi edilen hasta planı CC ve MC ile tekrar hesaplatıldı. Oluşturulan modele göre en küçük tümörlerde (PTV $<20 \mathrm{~cm}^{3}$ ), D95 dozunda \%20 doz azaltıldı (BED: 60-85), daha büyük tümörlerde (PTV >100 $\left.\mathrm{cm}^{3}\right)$ D95 dozunda $\% 10$ azaltıldı (BED $\left.>100\right)$. Akciğer ortalama dozlarında $\mathrm{CC}$ ve $\mathrm{MC}$ algoritmalarında doz \%15 daha düşük olarak bulmuşlardır. Küçük ve büyük boyutlu tümörlerde modele göre tekrar hesaplanıp BED değerleri incelendiğinde ve sonuçlar karşılaştırıldığında iki yıllık lokal kontrol arasında korelasyon bulunamamıştır. Çalışmanın sonucunda daha fazla veri ile çalışmayı genişletmeyi önermişlerdir (Chetty, 2013). Latifi ve ark. PB ve CC algoritmaları akciğer SBRT için incelemişlerdir. 201 Akciğer SBRT ile tedavi edilmiş hastaları retrospektif olarak tekrar incelemişler. Her bir hasta 5 fraksiyonda 50 Gy ile tedavi edilmiş. 201 Hastanın 116's1 PB algoritması ile 85 hasta ise CC algoritmas1 ile planlamışlar. Tüm planlarda hedef hacimeuygulanan dozun \%95'ini alması için normalize edilmiş. PB ve CC ile tedavi edilen hastalarda 17 ve 24 aylık medyan takip süreleri aynı bulmuşlar. Işınlanmış lezyonun lokal ve marjinal kontrolü de karşılaştırmışlardır. PB ile 25 hastada CC ile 4 hastada lokal nüks görülmüş, ama aradaki farklar istatistiksel olarak anlamlı bulamamışlardır. Sonuç olarak bu değerlerde birçok faktör olmasına rağmen PB algoritmasında dozu olduğundan daha fazla hesaplamasının da etkili olduğu düşünülmektedir (Latifi, 2014).

Küçük alanların kullanıldığı SRT/SBRT tedavilerinde TPS ve doz hesaplama algoritmalarının doğruluğu çok önemlidir. Doz dağılımının doğru hesaplanması için küçük alan ölçümleri ve hesaplama algoritmalarının hassasiyeti ile doğru orantılıdır. İnhomojen ortamlarda küçük alan dozimetrisinde ki belirsizlikler ve zorluklar daha da artmaktadır CC01 Razor iyon odas1 yeterince güvenilir sonuçlar elde edilmiştir. MC algoritması hem homojen hem de inhomojen fantomda altın standart olarak kabul edildiğinde, $1 \mathrm{x} 1 \mathrm{~cm}^{2}$ hariç CC ve PB algoritmaları ile uyum içerisindedir. Özellikle $1 \times 1 \mathrm{~cm}^{2}$ inhomojen fantom ölçümlerinde PB hesaplamaları ve CC04 iyon odası ile ölçümlerinde en büyük farklar gözlemlendiği için küçük alanların kullanıldığ 1 tedaviler ve ölçümlerde kullanılmaması önerilmemektedir. Yeni bir ticari ürün olan CC01 Razor iyon odası küçük alan dozimetrisi için uygun bir dozimetrik ekipmandır. 


\section{Kaynakça}

Almond P. R., Biggs P. J., Coursey B. M., Hanson W. F., Huq M. S., Nath R., Rogers D. W. O., 1999. AAPM's TG-51 Protocol for Clinical Reference Dosimetry of High Energy Photon and Electron Beams. Med. Phys. 26 (9).

Bruinvis I. A. D., Keus R. B., Lenglet W. J. M., Meijer G. J., Mijnheer B. J., 2005. NCS Report 15: Quality Assurance of 3-D Treatment Planning Sysytems for External Photon and Electron Beams. From https://radiationdosimetry.org/ncs/documents/ncs-15-3d-tpsfor-external-photon-and-electron-beams

Chen H., Lohr F., Fritz P., Wenz F., Dobler B., Lorenz F., Muhlnickel W., 2010. Stereotactic, Single-Dose Irradiation Of Lung Tumors: A Comparison Of Absolute Dose And Dose Distribution Between Pencil Beam And Monte Carlo Algorithms Based On Actual Patient CT Scans. International Journal Of Radiation Oncology Biology Physics. 78 (3): 955-963.

Chetty I. J., Devpura S., Liu D., Chen D., Li H., Wen N. W., Kumar S., Fraser C., Siddiqui M. S., Ajlouni M., Movsas B., 2013. Correlationofdose Computed Using Different Algorithms With Local Control Following Stereotactic Ablative Radiotherapy (SABR)Based Treatment Of Non-Small-Cell Lung Cancer. Radiother Oncol. 109:498-504.

Das I. J., Ding G. X., Ahnesjö A., 2008. Small Fields: Nonequilibrium Radiation Dosimetry. Med. Phys. 35 (1).

Das I. J., Cheng C. W., Ahnesjö A., Gibbons J., Li X. A., Lowenstein J., Mitra R. K., Simon W. E., Zhu T. C., 2008. Accelerator Beam Data Commissioning Equipmwnt and Procedures: Report of the TG-106 of Therapy Physics Committee of the AAPM. Med. Phys.35 (9).

Dobler B., Walter C., Knopf A., Fabri D., Loeschel R., Polednik M., Schneider F., Wenz F., Lohr F., 2006. Optimization Of Extracranial Stereotactic Radiation Therapy Of Small Lung Lesions Using Accurate Dose Calculation Algorithms. Radiat Oncol. 1:45.

Fraass B., Doopke K., Hunt M., Kutcher G., Strakschall G., Dyke J. V., 1998. American Association of Physicists in Medicine Radiation Therapy Committee Task Group 53: Quality Assurance for Clinical Radiotherapy Treatment Planning. Med. Phys. 25 (10). 
IAEA, 2017. Dosimetry of Small Static Fields Used in External Beam Radiotherapy. IEAE Technical reports series, Report 483.,ISSN 0074-1914; no. 483.

IAEA, 2004. Commissioning and Quality Assurance Computerized Planning Systems for Radiation Treatment of Cancer. IEAE Technical reports series, Report 430ISSN 00741914; no 430.

ICRU, 2017. Journal of the International Commission on Radiation Units and Measurements. Report 91.14 (2): 1-160. from https://doi.org/10.1093/jicru/ndx017

Khan F. M., 2010. The Physics Of Radiation Therapy 3rd Edition. Lippincott Williams \& Wilkins Company, USA.

Kim S. J., Kim S. K. \& Kim D. H., 2015. Journal Of The Korean Physical Society. 67: 153.Https://Doi.Org/10.3938/Jkps.67.153

Latifi K., Oliver J., Baker R, Dilling T. J., Stevens C. W., Kim J., Yue B., Demarco M., Zhang G., G., Fevgelman V., 2014. Study Of 201 Nonsmall Cell Lung Cancer Patients Given Stereotactic Ablative Radiation Therapy Shows Local Control Dependence On Dose Calculation Algorithm. Int. J. Radiat. Oncol. Biol. Phys. 88:1108-13.

Lax I., Panettieri V., Wennberg B., Duch M. A., Näslund I., Baumann P., Gagliardi G., 2006. Dose Distributions In SBRT Of Lung Tumors: Comparison Between Two Different Treatment Planning Algorithms And Monte-Carlo Simulation Including Breathing Motions. Acta Oncologica. 45(7) :978-988.

Lu L., 2013. Dose Calculation Algorithms İn External Beam Photon Radiation Therapy. Int J Cancer Ther Oncol. 1:01025.

Ma C. M., Li J. S., Deng J., Fan J., 2008. Implementation Of Monte Carlo Dose Calculation For Cyberknife Treatment Planning. Journal of Physics. 102 (1).

Wilcox E. E., Daskalov G. M., 2008. Accuracy of Dose Measurements and Calculations Within and Beyond Heterogeneous Tissues For 6 MV Photon Fields Smaller Than $4 \mathrm{~cm}$ Produced by Cyberknife. Med Phys. 35: 2259-2266. 